\title{
Determination of Characteristics of Dc Motors used in Light Motor Electric Vehicles using Inter- Operable Cad \& Femm
}

\author{
Dhananjaya B., Satyendra Kumar
}

\begin{abstract}
Electric vehicles (EV's) were invented and had been a part of transportation industry before 1900's. Being popular, they had good turn outs in the market till 1918. As the inventions of internal combustion engines grew in the transportation industry, EV's usage started to die. The usage of EV's was totally zero by 1933, due to slow response and high expenses. The shortcomings faced by EV's then, are not overcome totally till date. Advancement in the field of Microelectronics and power electronics have made $\mathrm{EV}$ power trains competitive with ICE power trains. The developments in the materials and manufacturing technologies provide optimistic battery. The vital factors that revive EV's: cost of energy, energy independency, pollution free operation. The upcoming shortage of fossil fuels, shortage of supply, growing demands and their cost have made people look around for an alternative mode of transportation. As electricity production can be made from different energy resources, $E V$ 's promise to be a future of vehicles. However the recharging can be done when there is excess energy in power utilities. The biggest reason of interest towards $E V$ 's is environmental factors such as reduction in air pollution in congested traffics thereby meeting national energy strategy policies

Index Terms: EV, ICEV, PMBLDC Motor, FEM.
\end{abstract}

\section{I.INTRODUCTION}

Electric vehicles (EV's) were invented and had been a part of transportation industry before 1900's. Being popular, they had good turn outs in the market till 1918. As the inventions of internal combustion engines grew in the transportation industry, EV's usage started to die. The usage of EV's was totally zero by 1933, due to slow response and high expenses. The shortcomings faced by EV's then, are not overcome totally till date. Advancement in the field of Microelectronics and power electronics have made $\mathrm{EV}$ power trains competitive with ICE power trains. The developments in the materials and manufacturing technologies provide optimistic battery. The vital factors that revive EV's: cost of energy, energy independency, pollution free operation. The upcoming shortage of fossil fuels, shortage of supply, growing demands and their cost have made people look around for an alternative mode of transportation. As electricity production can be made from different energy resources, EV's promise to be a future of vehicles. However the recharging can be done when there is excess energy in power utilities.

Revised Manuscript Received on February 15, 2020.

* Correspondence Author

Dhananjaya B, Assistant Professor grade in the Department of EEE at Canara Engineering College Mangalore.

Dr.Satyendra Kumar, Professor grade in the Department of EEE at NMAMIT, Nitte

(c) The Authors. Published by Blue Eyes Intelligence Engineering and Sciences Publication (BEIESP). This is an open access article under the CC BY-NC-ND license (http://creativecommons.org/licenses/by-nc-nd/4.0/)
The biggest reason of interest towards EV's is environmental factors such as reduction in air pollution in congested traffics thereby meeting national energy strategy policies. The reduction in the quality of air and the emanative effects of greenhouse has made some authorities to set emission-free zones and enforce strict regulations, to promote EV's. EV evolution aims to build merchandising EV's over long period, providing performance, personal luxury, secure, facile operation like ICE counterparts at competitive cost. On this state-of- affairs the evolution of high-performance, mediocre, reliable EV's with better performing batteries are very much needed. The evolution of power train that has high power density, high- efficacy and blended electric propulsion is essential. The torque-speed curve of the drive comprises constant torque region for starting/climbing and constant power region for cruising. It is learnt from literature survey that the bigger vehicles needs smaller torque, power and continuous speed. During early 1900's, EV's failed to meet these specifications resulting the peak speed and performance parameters of the EV's failing to compete on-par with ICEV in urban and rural traffic. The design of EV concentrates on Energy system and Management. The objective of the work is to compare different motors such as PMBLDC, DC and AC using Finite Element Method (FEM) and to build motors with immense power density and efficiency \& to develop drives for EV exercise.

FEM primarily determines the fields due to electric and magnetic energy distribution. The entire analysis domain gets divided into small elementary sub-domains, called Finite Elements. It permits analysis of dangerous field gradient, magnetic field strength, saturation etc. reducing computation time. The analysis carried out leads to accurate results due to consideration of air gap.

\section{II.INTRODUCTION TO AUTOCAD}

Automatic Computer Aided Design (AutoCad) tool is developed and marketed by Autodesk Inc. It is used for design and drafting of 2-Dimensional and 3-Dimensional layouts. AutoCad being the first CAD program to be executed on personal computer is used in the industry by electrical, Civil, Mechanical engineers and other professionals. The early release had only primitive entities for the construction of complex commodity. Further the support was extended to custom objects through a interface based on $\mathrm{C}++$ application programming. The Latest version incorporates tools for solid modeling. It also contains 3Dimensional support application program interface for automation and object customization. DWG (Drawing) and DWF (Design Web Format) are the native file format in AutoCAD for CAD data interoperability. It 
is a format developed by Autodesk for publishing CAD data.AutoCAD provides professionals a exclusive drafting tool to bring their unique engineering ideas to reality with the perfection. In this bulge, AutoCAD provides a platform to design mechanical elements, analyze electrical and piping systems and decipher design issues. AUTOCAD helps in engineering elements drawings, design of infrastructure and study of HVAC systems with minimal errors contributing a major part in engineering fields. AutoCAD also supports export of files through its interface to CAD applications to assist building animation projects, structures and architectural plans reducing the production cost. CAD interface helps industries to draft real-time prototypes of object virtually and test the operation during the design process. AutoCAD assists the design of initial prototype and simulate the working before the actual production. The virtual prototype can be used by the designers for presentations during advertising.

\section{III.INTRODUCTION TO FEMM}

FEMM is a package of programs for solving low frequency electromagnetic problems on 2D planar and 3D axisymmetric. The program articulates problems like linear/nonlinear magneto- static, linear/nonlinear time harmonic magnetic, linear electrostatic, and steady-state heat flow.

FEMM has three major divisions:

Interactive shell (femm.exe). This suite is a Multiple Document Interface for the different types of problems solved by FEMM. It has a interface similar to CAD to draw the outline of the issue to be addressed, to define properties of material and periphery conditions. DXF files are imported from AUTOCAD to analyze existing design .This allows the display of field solutions in terms of contour and density. It permits the user to inspect field strength in arbitrary points and calculate different integrals with plotting of various quantities along defined contours.

Triangle.exe.:being a vital part of FEMM splits down the elucidation region into smaller triangles of various numbers. Solvers(fkern.exe: for magnetics; belasolv: for electrostatics, hsolv: for heat flow problems and csolv: for current flow problems) The values of desired fields are obtained by solving the partial differential equations from the data set describing the problem.

A scripting language called "Lua" is embedded into the interactive shell. The latest version of FEMM entertains only one instance of scripting language to be running at a time. This helps in developing and analyzing the layout, thereby evaluating the post processing outcomes. The mathematical expressions and equations are entered into the edit boxes of user interface with the corresponding numerical values. The expressions and equations in any edit boxes can be evaluated by using selection menu through the right button of the mouse.

This aims at giving a brief description to the user regarding the problems that FEMM solves. Here enough boundary conditions are assigned to pointers to get a solvable problem.

Assumptions are made between electromagnetism Maxwell's, since the material cannot be reviewed within the scope of the. Several references have been found to understand the derivation and solution of Maxwell's equations. Plonus's Applied electromagnetic is a good introductory level understanding for magnetic and electromagnetic problems. Hoole's Computer-aided analysis and design of electromagnetic devices gives intermediate level views on Maxwells equations. Jackson's Classical electrodynamics provides advanced treatment. White's Heat and mass transfer for Thermal problems and Haberman's Elementary applied partial differential equations to understand the derivation and solve steadystate temperature problems.

\section{IV.METHODOLOGY}

\section{DXF IMPORT/EXPORT}

Import/Export is a common feature available with all modes of preprocessor. FEMM allows only 2D DXF files to be imported effectively.

To start the import, select Import DXF off of the File menu. A dialog box asking for tolerance will appear. This tolerance defines maximum distance between two points. The default tolerance values are enough, however at times it has to be increased to facilitate importing. FEMM cannot get all tags in the DXF file. It strips the commands included with geometry and rest are ignored.

DXF import facilitates the user to sketch any layout using the CAD package. The layout is sketched, and imported to FEMM. Details such as properties of material and boundary conditions are to be defined. The importing process will be time consuming as the process needs to do lot consistency checks to convert the DXF file into finite element geometry. The final geometry will be exported to DXF form by choosing the option from menu in the preprocessor window, which in turn is imported to Cad package to assist the mechanical detailing for final design.

\section{Specifications of Light electric Vehicle}

Vehicle Mass including Commuter
Max Power Output
Battery
Tyre size
City estimated Range
Top Speed
Acceleration

$200 \mathrm{Kg}$

$1.5 \mathrm{KW}$

$2.16 \mathrm{KWh}$

1000 Â 300

$50 \mathrm{Km}$

$50 \mathrm{Kmph}$

$0.65 \mathrm{M} / \mathrm{s}^{2}$ 
Drag Co-efficient

Technical Specifications of Motor drive

\section{Rated Voltage \\ Rated Power \\ Rated Torque \\ Rated Speed \\ Rated Current \\ Max Current \\ Max Torque \\ Motor Length \\ Motor weight \\ SQUIRREL CAGE INDUCTION MOTOR}

After drawing the two dimensional figure of the squirrel cage induction motor in Auto-Cad to the required dimensions and importing it to the FEMM Software.

There are following steps to be followed

1. Inserting of materials for Squirrel Cage Induction motor This is the inserting step. Under this we insert the various materials of the stator and Rotor by selecting the materials from the library. It also includes the steps to inserting the number of turns and supply current. We selected the boundary condition as air.

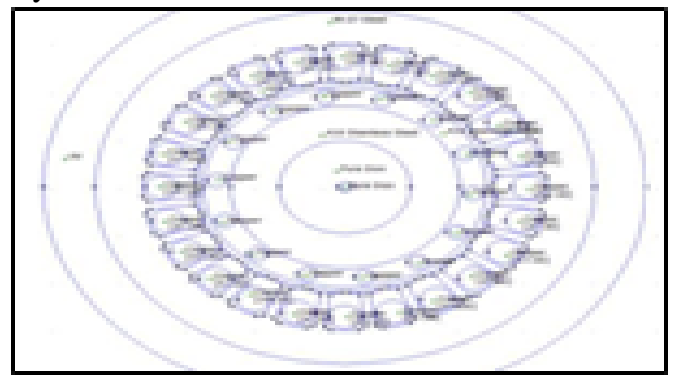

Fig1.Insertion of materials using CAD

2. Creating the mesh and run the crank case

i) Process of generating mesh

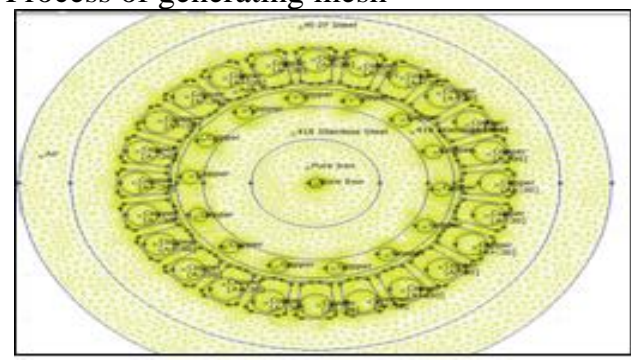

Fig 2.Mesh Creation

ii) After the completion of generating mesh proceed with crank solutions.

The mesh is generated only when the closed area is filled by specified materials. If any part is not specified then the mesh will not be generated.

$$
\begin{gathered}
48 \mathrm{~V}(\mathrm{DC}) \\
500 \mathrm{~W} \\
1.27 \mathrm{~N}-\mathrm{m} \\
3000 \mathrm{Rpm} \\
11.4 \mathrm{~A} \\
34.2 \mathrm{~A} \\
3.81 \mathrm{~N}-\mathrm{m} \\
130 \mathrm{~mm} \\
1.67 \mathrm{~kg}
\end{gathered}
$$

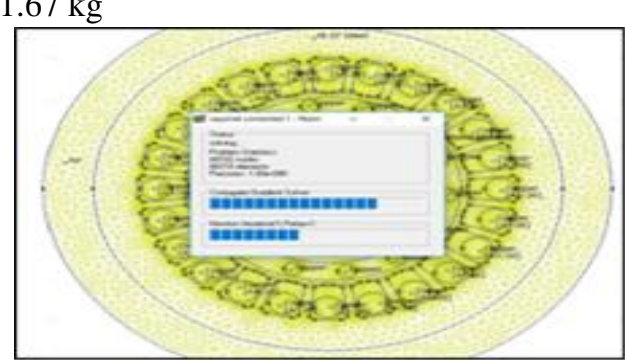

Fig3. Running mesh for crank solution

3.Flux Lines Generation

Once the mesh is generated the flux lines can be observed. The below graph represents the magnetic flux lines across the motor.

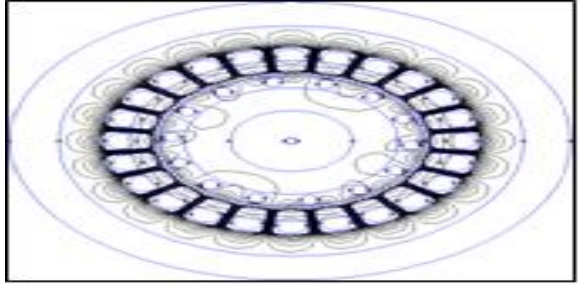

Fig 4.Generated flux lines

4.Selecting the area across the motor to get the characteristics required

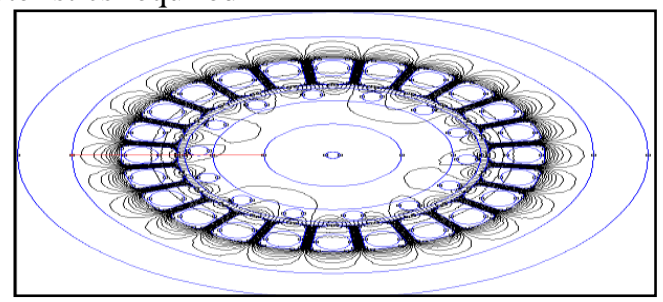

Fig 5.Area selection for characteristic

5. Checking the flux density

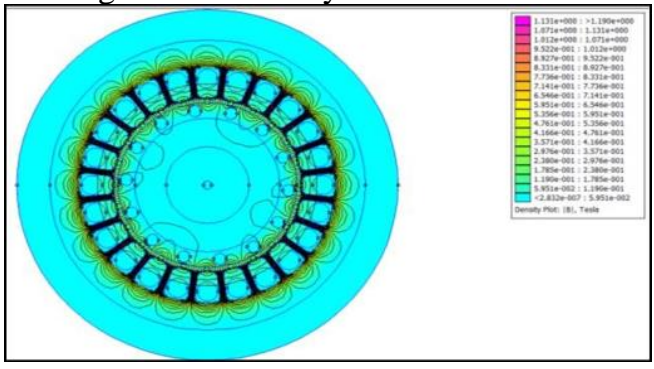

Fig 6.Flux density

6. Grey scale representation for flux density distribution

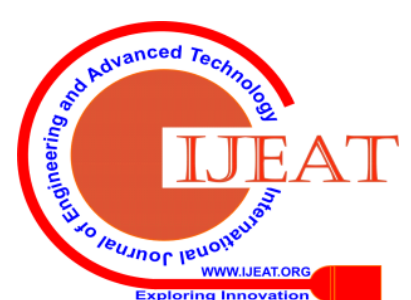




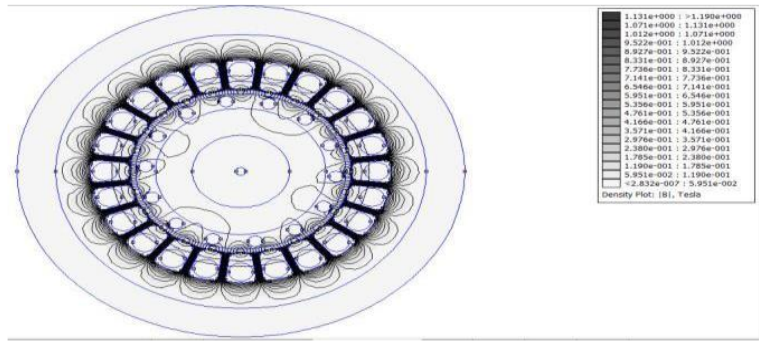

Fig 7. Grey scaling of flux density

This is the method used to calculate the magnetic field co energy in the motor. Here we will get an option to select the area, we need to calculate the magnetic field co-energy.

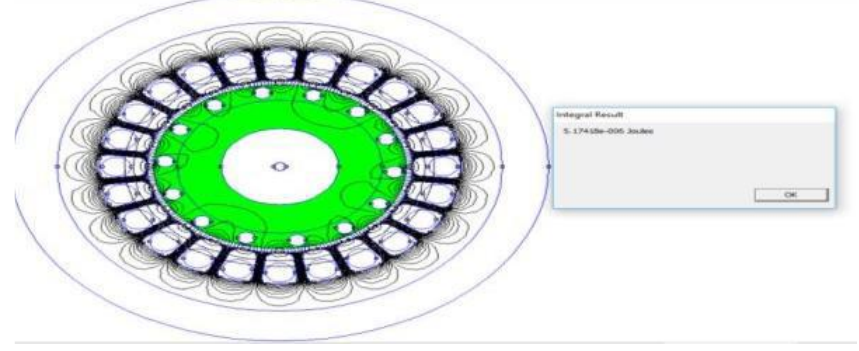

Fig.8. Magnettic Field co-energy

8. Calculation of Magnetic field energy

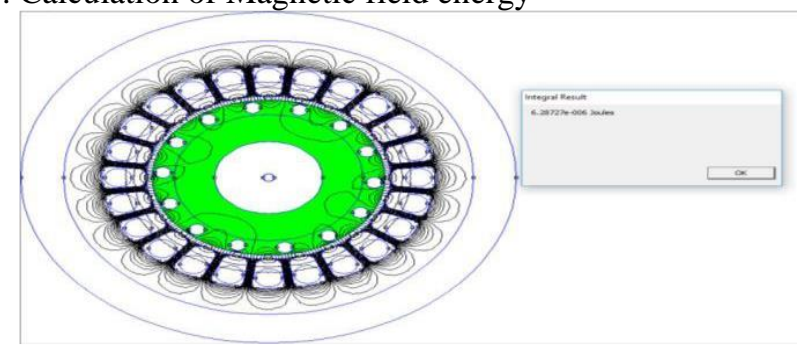

Fig 9. Calculation of Magnetic field energy

Plot of magnitude of Magnetic flux density vs length of selected line This is the magnitude of Magnetic flux density vs length of selected line plot. The initial peak of the curve represents the magnetic flux density in the stator. Next decrease in the waveform represents the flux cutting in the conductors. The second peak gives us the value of flux lines present in the air gap.

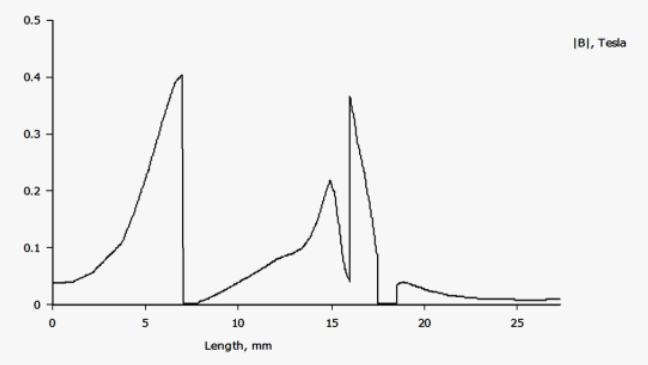

Fig 10. Plot of magnitude of Magnetic flux density vs length of selected line

Plot of Magnitude of Magnetic field intensity vs length of selected lines This is the graph representing the magnetic field intensity v/s length of selected line. The peak value represents the value of maximum field intensity across the selected line.

Retrieval Number: B4033129219/2020@BEIESP
After drawing the two dimensional figure of the squirrel cage induction motor in Auto-Cad to the required dimensions and importing it to the FEMM Software.

These are following steps to be followed

1. 1.Inserting of materials for BLDC motor

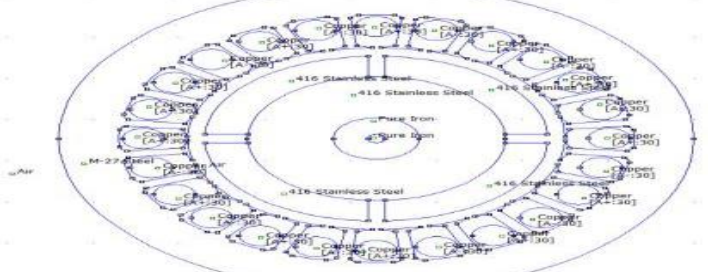

Fig 12. Insertion of materials using CAD

2. Creating the mesh and run the crank case

i) Process of generating mesh

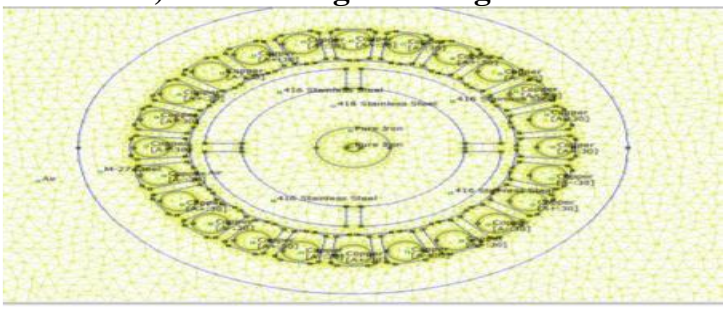

Fig 13. Mesh Creation

After the completion of generating mesh proceed with bcrank solutions, The mesh is generated only when the closed area is filled by specified materials only then it can be preceded. If any part is not specified then the mesh will not be generated.

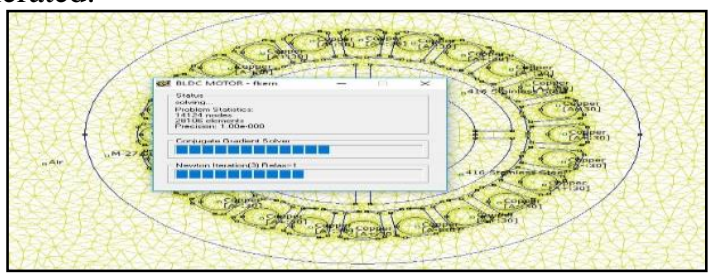

Fig 14. Running mesh for crank solution

3. Checking the flux density

This step is useful to get the flux density across the motor. The area which is shown by the pink color is the higher flux density regions. The area which is shown by blue color is lighter flux density areas

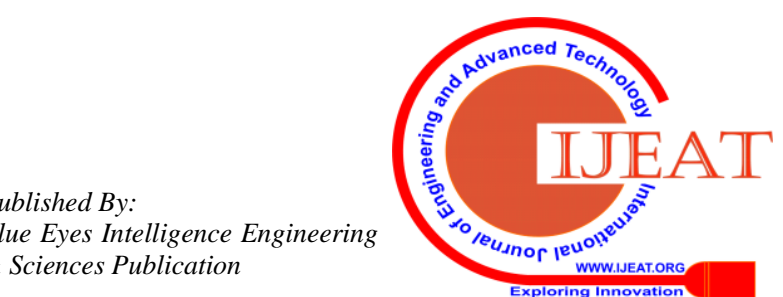




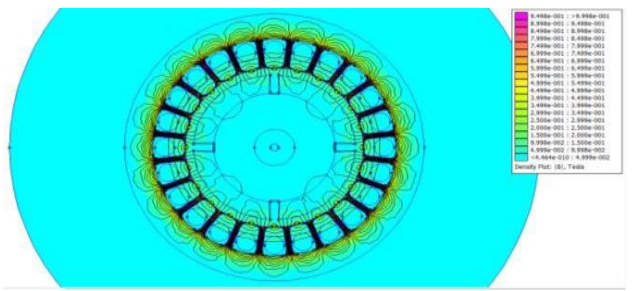

Fig 15. Flux density

4. Selection of area across the motor to get the required characteristics This is the very important step to get the required characteristics of the motor. Here we select the area across the motor where we need to get the required plot.

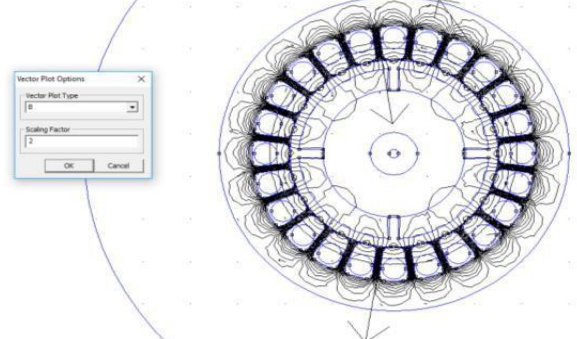

Fig 16. Area Selection for characteristic

5. Grey scale representation for flux density across the motor.

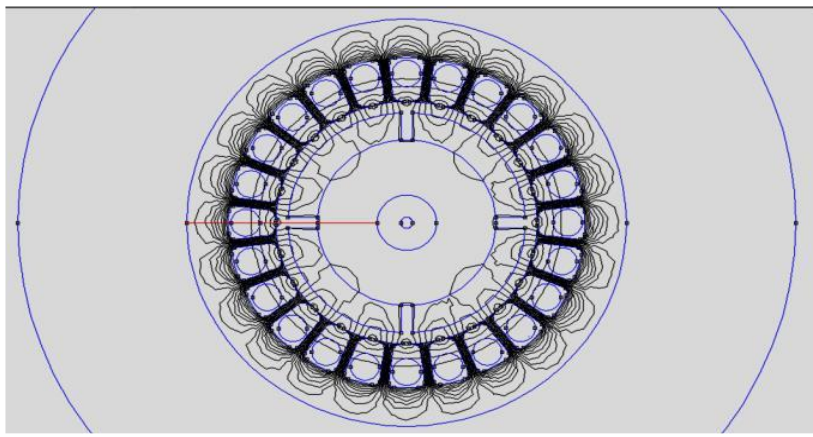

Fig 17.Grey Scale representation of Flux density field

6. Finding the vector direction of Magnetic field
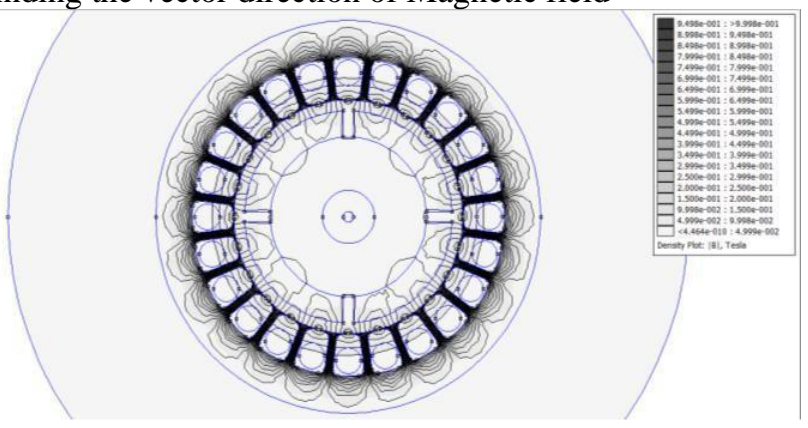

Fig 18. Vector direction of field

7. Calculation of Magnetic field co energy

This is the method used to calculate the magnetic field co energy in the motor. Here we will get an option to select the area we need to calculate the magnetic field co-energy.

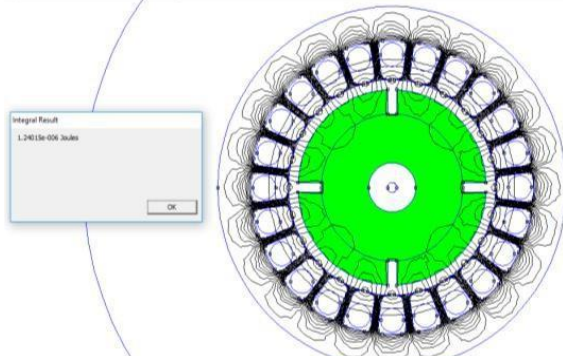

Fig 19. Magnetic field co-energy calculation

Retrieval Number: B4033129219/2020@BEIESP
Fig 20.Magnetic field energy calculation

9. Plot of Magnitude of Magnetic field intensity v/s length of selected line

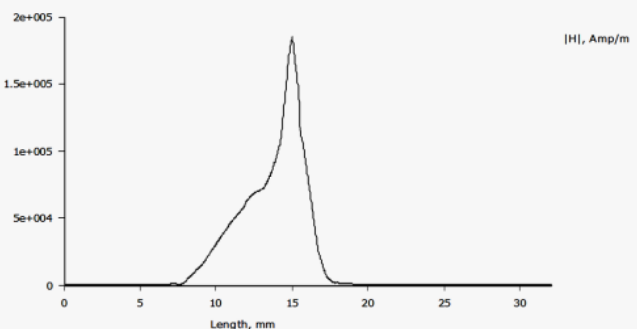

Fig 21. Plot of Magnitude of Magnetic field intensity v/s length of selected lines

PMBLDC MOTOR

PMBLDC motor is a permanent magnet brushless DC or. After drawing the two dimensional figure of the permanent magnet brushless DC motor in Auto Cad to the required dimensions it is imported to the FEMM Software.

1. Inserting the materials of different parts of PMBLDC motor

This is the inserting step. Under this we insert the various materials of the stator and Rotor by selecting the materials from the library. It also includes the steps to inserting the number of turns and supply current. We selected the boundary condition as air

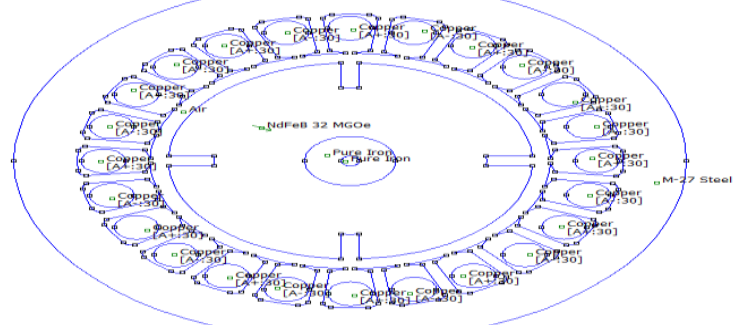

Fig 22.Material insertion using CAD

2. Creating the Mesh for PMBLDC motor and crank case running

i) Generating the mesh for PMBLDC motor

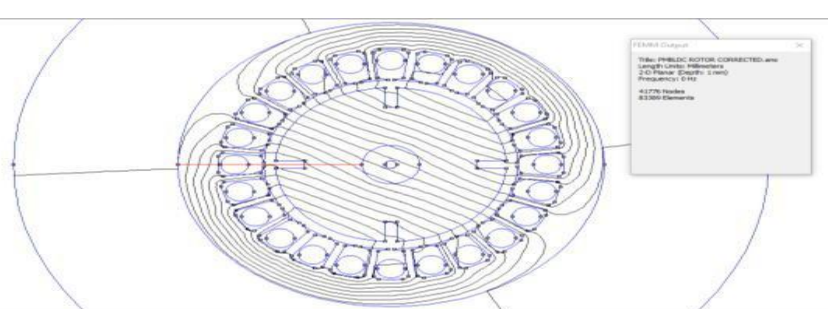

Fig 23. Mesh Creation

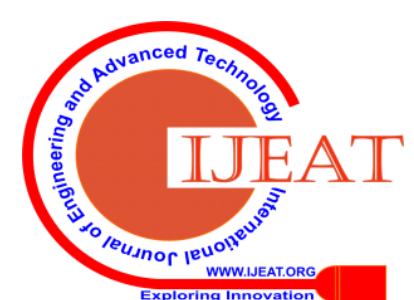


ii) After the completion of generating mesh proceed with crank solutions

The mesh is generated only when the closed area is filled by specified materials. If any part is not specified then the mesh will not be generated.

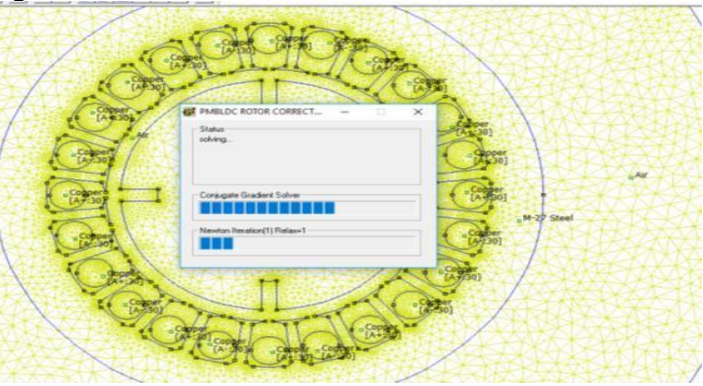

Fig 24. Running mesh for Crank Solution

3. Checking flux density

After the creation of mesh the flux lines distributed across the motor can be observed. Since it is a PMBLDC motor we

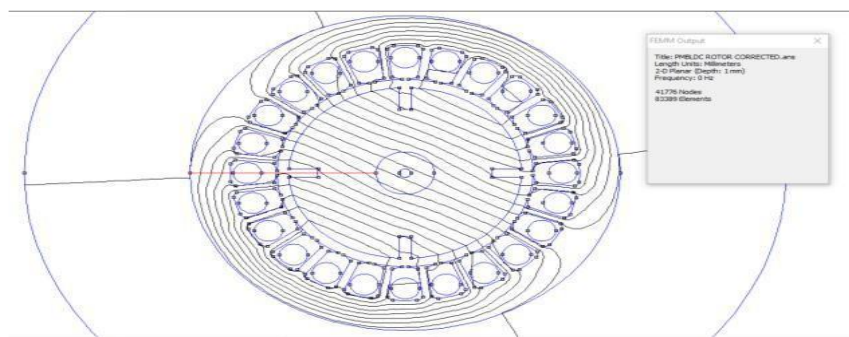

can observe the more number of flux lines cutting the rotor

Fig 25. Flux distribution

4. Selection of area across the motor to get the required characteristic curves

This is the very important stage. In this we draw a line through where we need to calculate the necessary parameters like magnetic flux density and magnetic field strength.

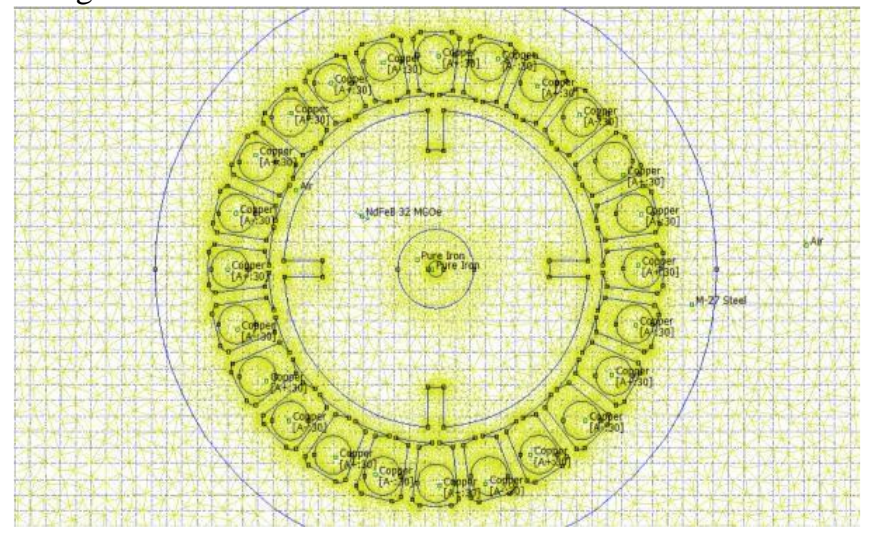

Fig 26. Area selection for characteristics

5. Grey scale representation for flux density distribution The grey scale plot is similar to the density plot it helps in the better understanding of the magnetic flux density

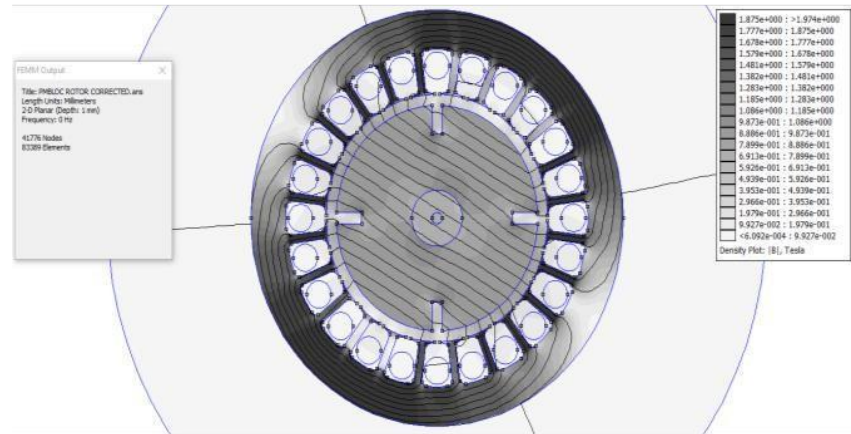

Fig. 27 Grey scale representation for flux density distribution

6. Finding the vector direction of Magnetic field It is used to get the magnetic field vector showing the directions of the field lines across the stator and rotor.

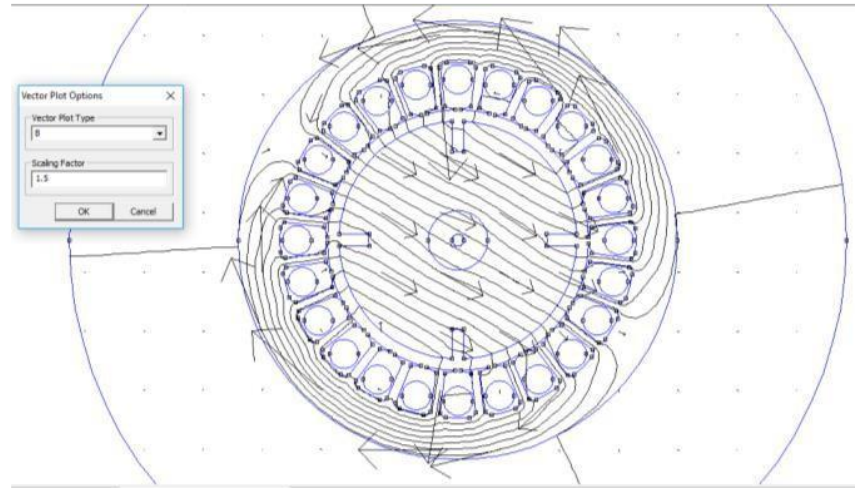

Fig. 28. Vector direction of Magnetic field

7. Calculation of Magnetic field co energy

This is the method used to calculate the magnetic field co energy in the motor. Here we will get an option to select the area we need to calculate the magnetic field co energy.

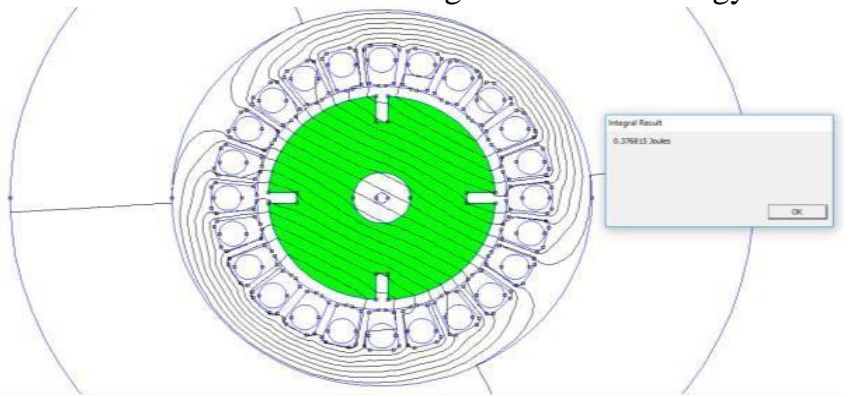

Fig 29. Magnetic field co-energy calculation 8. Calculation of Magnetic field energy

This is similar to the magnetic field co energy calculation. We select the area across motor where we need to calculate the magnetic field energy

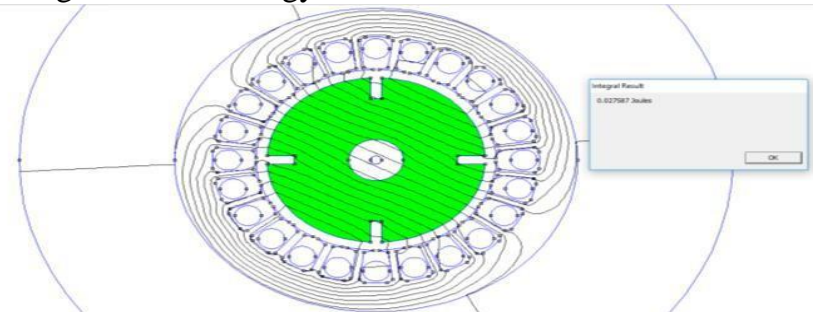

Fig. 30. Magnetic field energy calculation

Published By: 
9. Plot of Magnitude of Magnetic field intensity vs length of selected lines

This is the graph representing the magnetic field intensity $\mathrm{v} / \mathrm{s}$ length of selected line. The peak value represents the value of maximum field intensity across the selected line.

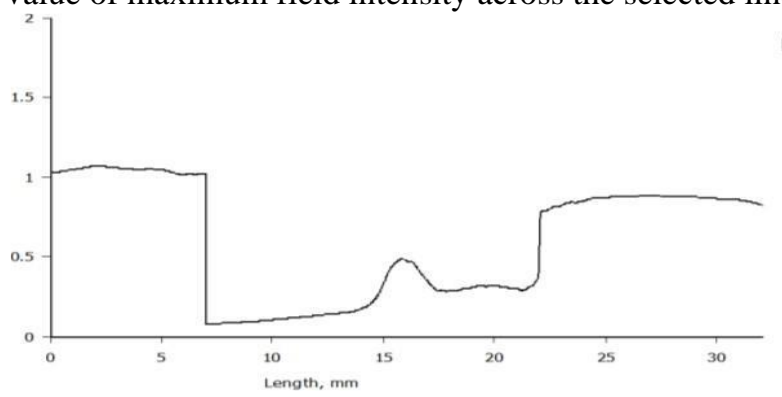

Fig. 31. Plot of Magnitude of Magnetic field intensity vs

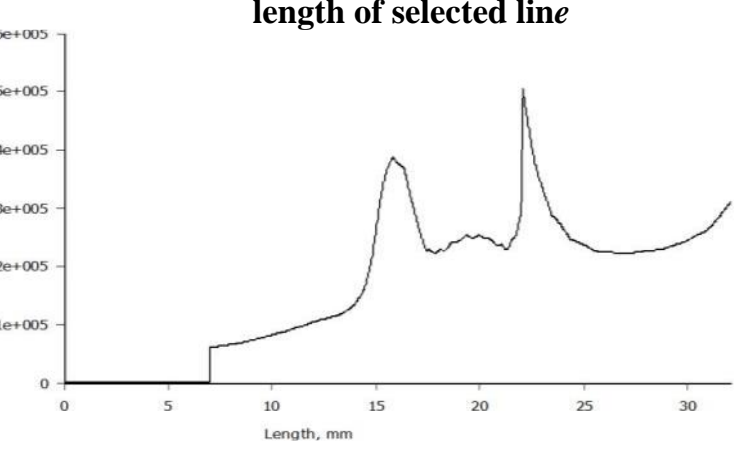

Fig.32.Plot of magnetic field density vs length of selected line

\section{V.RESULTS}

Comparison between the Motors

Table 1.Comparison of characteristics of Motors

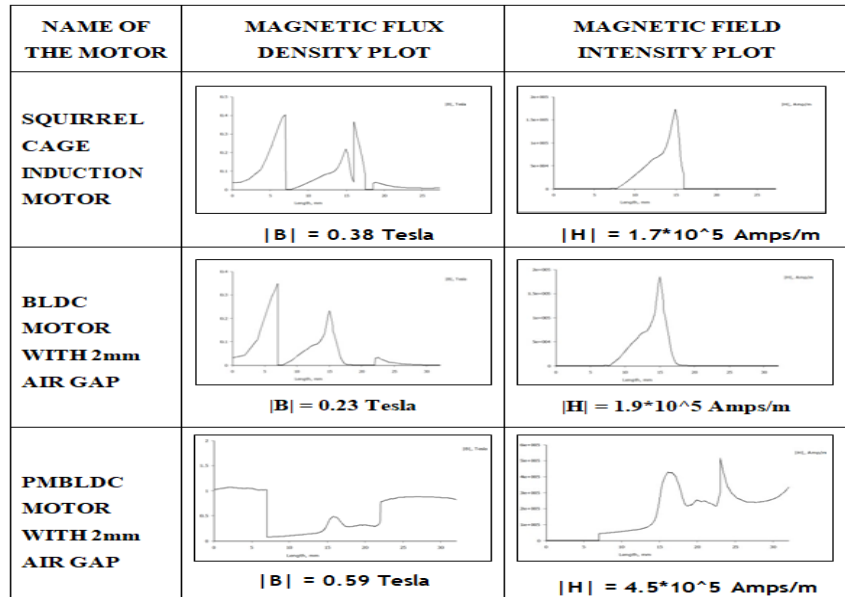

\section{VI.CONCLUSION}

In PMBLDC motor the magnetic field intensity is greater thus indicating that the variation of flux still does not give major problems to the electric vehicle. The Magnetic Flux Density(b) tesla value is considerably high thus proving it to be more highly efficient and reliable.The comparison of the squirrel cage induction motor, blushless dc motor and permanent magnet brushless dc motor is completed successfully. The efficient motor that is permanent magnet brushless dc motor in the project is obtained. The comparison done and concluded that PMBLDC is best suited for the electric vehicle because of its uniform flux distribution characteristics and torque characteristics. The comparison study between squirrel cage induction motor, BLDC and squirrel cage induction motor, BLDC and PMBLDC we can choose PMBLDC for uniform flux density. This study is based on flux distribution without applying load. The future scope is to improve by changing air gap and also doing 3 dimensional analysis for speed torque.

\section{REFERENCES}

1. E. Kaliappan ,C. Sharmeela \& Sayee Krishna.A.V,"Direct Torque Control of PMBLDC motor using Hybrid (GA and Fuzzy logic) controller", November, 2010.

2. K.Soorya and S.Assly Steffy "Analysis And Simulation Of Speed Control Of PMBLDC MOTOR by PI Controller" International Journal of Advanced Research in Computer and Communication engineering Electrical, ISSN: 2320-2084 Volume-3, Issue-2, february.-2014.

3. Dr.Satyendra Kumar M and Udaykumar R Y,"Stability analysis of NOVEL PMBLDC motor drive for electric scooter application", 2016 IEEE

4. Dr.Satyendra Kumar M and Latha Shenoy, "Design Topology and Electromagnetic Field Analysis of Permanent Magnet Brushless DC motor.

5. Hanif F. Prasetyo,Arief S. Rohman, Farkhad I. Hariadi, Hilwadi, "Controls of BLDC Motors in Electric Vehicle Testing Simulator", ICSET : 2016

6. SS Srinivas K \& P.Pavankumar, "Enhancement of Dynamic performance of brushless DC Motor Drive", IEEE 2017

7. Dr. Satyendra Kumar M \& Shripad T. Revankar, "Development scheme and key technology of an electric vehicle: An overview",April 2017.

8. M. Fasil, N. Mijatovic, B. B. Jensen, and J. Holboll , "Finite-Element Model- Based Design Synthesis of Axial Flux PMBLDC Motors",2015

9. Ravikiran Hiremath , B.A. Sridhara, "Finite Element Analysis of BLDC motor"

10. T. H. Akinaga, C. Pompermaier, F. J. H. Kalluf and M. V. Ferreira da Luz"Performance Evaluation of Brushless DC Permanent Magnet Motor Using Finite Element Method”. August $1^{\text {st }}, 2018$.

11. K. T. Chau and Chunhua Liu "Overview of Permanent-Magnet Brushless Drives for Electric and Hybrid Electric Vehicles", 2008.

12 Nasser Hashernnia and Behzad Asaei "Comparative Study of Using Different Electric Motors in the Electric Vehicles", 2008

13. Wang Xiaoyuan and Wang Pingxin "The Magnetic Field Analysis of Permanent Magnet Synchronous Motor Used in Pure ElectricVehicle Based on FEM", 2010

14. Ion Boldea and N. Tutelea "Automotive Electric Propulsion Systems With Reduced or No Permanent Magnets: An Overview", IEEE, 2014.

15. Jun-Hyuk Choi, Joon Sung Park "Control Scheme for Efficiency Improvement of slim type BLDC Motor”, IEEE, 2014

16. Mr. Anurag M. Lulhe "A Technology Review Paper for Drives used in Electrical Vehicle (EV) \& Hybrid Electrical Vehicles (HEV)",July 2016.

17. Tae-Yong Lee, Myung-Ki Seo, Yong-Jae Kim, Sang-Yong Jung, Member, IEEE "Motor Design and Characteristics Comparison of Outer-Rotor type BLDC Motor and BLAC Motor Based on Numerical Analysis", IEEE, June 2016.

18. Y.B. Adyapaka Apatya, Aries Subiantoro and Feri Yusivar, "Design and Prototyping of 3- Phase BLDC Motor", Published in 2017 in $15^{\text {th }}$ international conference.

19. B. V. Ravi Kumar and K. Siva Kumar "Design of A New Dual Rotor Radial Flux BLDC Motor with Halbach Array Magnets for an Electric Vehicle", IEEE, 2016

20. S.Sakunthala, Dr. R.Kiranmayi, Dr. P.Nagaraju Mandadi “A Study on Industrial Motor Drives(Comparison and Applications of PMSM and BLDC Motor Drives)",2017

21. B. V. Ravi Kumar and K. Siva Kumar "Design of A New Dual Rotor Radial Flux BLDC Motor with Halbach Array Magnets for an Electric Vehicle", IEEE, 2016 
22. S.Sakunthala, Dr. R.Kiranmayi, Dr. P.Nagaraju Mandadi “A Study on Industrial Motor Drives(Comparison and Applications of PMSM and BLDC Motor Drives)",2017

21. P.Suganthi, S. Nagapavithra , S. Umamaheswari "Modeling and Simulation of Closed Loop Speed Control for BLDC Motor”, 2017

22. Rahat Ullah Khan "Real Time Performance Evaluation of Modified PMDC Motor, BLDC Motor and Dual Commutator PMDC Machine",IEEE, 2017.

23. Mohsen Ebadpour,Mohammad Bagher Bannae Sharifian, Ebrahim Babaei "Modeling and control of dual parallel BLDC motor drive system with single inverter", IEEE, 2017.

24. Shinn-Ming Sue,Kun-Lin Wu, Jhih-Sian Syu, Kuo-Cheng Lee "A phase advanced commutation scheme for IPM-BLDC motor drives", IEEE, 2009

25. Lekshmi Arun, Ananthu Vijayakumar "An active torque control strategy for cost effective BLDC motor drive", IEEE, 2017.

26. K.M. Rahman, S.E. Schulz "Design of high efficiency and hightorque- density switched reluctance motor for vehicle propulsion", IEEE, 2002.

27. Petre-Marian Nicolae ; Eusebiu-Florian Bida "Aspects regarding the simulation of an electric drive pm motor used in light electric vehicles", IEEE, 2016.

28. T. H. Akinaga, C. Pompermaier, F. J. H. Kalluf and M. V. Ferreira da Luz "Performance Evaluation of Brushless DC Permanent Magnet Motor Using Finite Element Method”, IEEE, 2011.

29. M. Fasil, N. Mijatovic, B. B. Jensen, and J. Holboll "Finite-Element Model- Based Design Synthesis of Axial Flux PMBLDC Motors", IEEE, 2016.

30. Teeradej Srisiriwanna and Mongkol Konghirun “A Study of Cogging Torque Reduction Methods in Brushless DC Motor”, IEEE, 2012.

31. Gang Lei, You Guang Guo, Jian Guo Zhu and Wei Xu "An Optimal Flux- Switching Permanent Magnet Machine for Hybrid Electric Vehicles", IEEE, 2015.

32. Yiguang Chen, Lingbing Kong, and Weigang Zhong "Finite Element Analysis of Interior Composite-Rotor Controllable Flux Permanent Magnet Synchronous Machine", IEEE, 2009.

33. Daniel Fodorean and , Lorand Szabo "Control of a Permanent Magnet Synchronous Motor for Electric Scooter Applications", IEEE, June 2012.

\section{AUTHORS PROFILE}

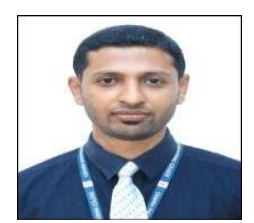

Dhananjaya B is presently working in the Assistant Professor grade in the Department of EEE at Canara Engineering College Mangalore. He has pursued his Bachelor degree in EEE and M.Tech in Microelectronics and Control systems from VTU, Belagavi. He is presently pursuing his Doctoral studies in the field of Motors and Drives, His areas of interest are Power Electronics, Micro-Electronics, Motor Drives and Electric vehicles.

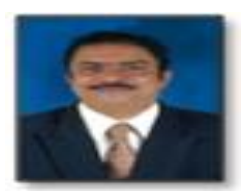

Dr.M Satyendra Kumar Shet is presently working in the professor grade in the department of EEE at NMAMIT, Nitte. He has pursued his Bacheor degree in electrical from Mangalore university. M.Tech in Power Electronics from Bangalore University and Doctoral Degree in Power Electronics and Drives from NITK, Suratkal. His areas of interest are Power Electronics \& Drives, Renewable energy Systems, switch mode power converters, Energy audit and energy management and Electric Vehicles. 